\title{
A EDUCAÇÃO FEMININA NA FRONTEIRA DA AMAZÔNIA: ESCOLAS PARA AS MULHERES NO EX- TERRITÓRIO FEDERAL DO AMAPÁ (1949-1964)
}

\author{
Tatiana Pantoja Oliveira \\ Norma-Iracema de Barros Ferreira \\ Universidade Federal do Amapá (UNIFAP), Macapá, Amapá, Brasil
}

Resumo: O presente trabalho contextualiza o debate sobre a educação feminina no Brasil e no Amapá, conjugando a pesquisa bibliográfica e a empírica, utilizando metodologia da História Oral para análise das entrevistas semiestruturadas, concedidas por 9 ex-alunas da Escola Doméstica de Macapá, além dos relatos da 10a egressa, condensados em uma autobiografia. Apresenta um dos resultados da dissertação de mestrado Público/confessional, cultura escolar e formação de habitus: a Escola Doméstica de Macapá/AP (1951-1964), versando sobre a incorporação de habitus por meio da cultura escolar da referida escola. O embasamento teórico revestese do conceito de habitus, de Pierre Bourdieu, e de cultura escolar, de Dominique Julia.

Palavras-chave: Estado. Igreja Católica. Educação Feminina. Cultura Escolar. Habitus.

INTRODUÇÃO

Cada instituição escolar tem uma historicidade própria, sofrendo mudanças decorrentes das várias épocas históricas nas quais está circunscrita. Assim, ela pode atender a públicos diferentes e apresentar alterações na sua linha pedagógica ao longo dos anos. Assim também a Escola Doméstica de 
Macapá não pode ser dissociada de sua dimensão histórica. Por ter sido uma escola eminentemente feminina, as discussões sobre gênero perpassaram a constituição de sua cultura escolar.

Dois conceitos operacionais são fundamentais para se entender a análise que se apresenta neste trabalho: o conceito de habitus, de Pierre Bourdieu e o conceito de cultura escolar. Uma das muitas contribuições que Bourdieu (2011) legou para as ciências humanas reside justamente em pensar de que forma os grupos sociais criam formas de diferenciação entre si na disputa em que se envolvem pela hegemonia dos campos e articulam estratégias de reprodução dessas diferenciações, e como se dá a incorporação do sistema de disposições - o habitus. A educação constitui-se como parte dessas estratégias, ou a melhor dessas, na consecução de seus objetivos. Os postulados de Bourdieu nos fazem refletir de que forma a mulher foi imbuída de concepções de gênero em sua formação educacional pelo Estado brasileiro.

Outro conceito éo de cultura escolar, alicerçado nos encaminhamentos propostos por Dominique Julia (2001). As instituições escolares criam suas regras e normas de modo a tentar que o educando assimile não apenas conhecimentos, mas também práticas que incorporem comportamentos. A escola não pode ser vista como um joguete de forças externas, na medida em que ela tem sua dinâmica própria. O voltar-se para dentro da escola, procurando seus acervos, se estende também, como foi possível neste trabalho, ao trabalho de História Oral, ouvindo dos próprios sujeitos a quem se destinava a educação, no caso as ex-alunas da Escola Doméstica de Macapá, suas percepções e relatos sobre a cultura escolar e a incorporação de habitus.

\section{EdUCAÇÃO FEMININA NO BRASIL}

Desde o período colonial do Brasil foi evidente a exclusão das mulheres do sistema educacional, as quais foram relegadas à atuação no espaço doméstico. Para Stamatto $(2002$, p. 3), não se concebia a "inserção feminina em uma atividade pública, já que a sociedade da época concebia a mulher para o casamento, ou para a vida religiosa, ou para o trabalho doméstico e escravo, práticas que precisavam de pouca ou nenhuma educação escolar." Por sua vez, Azzi $(2008$, p. 38) discutiu essa inserção da mulher como esposa e propriedade do marido, uma vez que ela vivia "inteiramente submissa ao seu domínio". A única preocupação era com sua formação religiosa, para que transmitisse a fé católica de geração para geração.

Conforme Cunha e Silva (2010, p. 99), observa-se que a mudança nessa concepção pode ser apontada a partir da vinda da família real para o Brasil, que permitiu a expansão da educação e o ingresso de meninas na vida 
escolar, desde que em classes separadas dos estudantes masculinos. A principal finalidade era formação de professoras em Escolas Normais, com ênfase nas aptidões femininas e não na capacidade intelectual, e na criação de uma rede de assistência confessional filantrópica para o ensino de prendas domésticas.

O início do século XX foi outro momento em que a educação feminina voltou a ser alvo de preocupação, agora sob uma ótica diferente. Manoel (1996) apontou que para a elite da época, além da conjugação de boas esposas/donas de casa/mães, era exigido que as mulheres fossem mais sociáveis e tivessem polimento cultural. Quem passou a cuidar desse papel foram os colégios femininos católicos, em regime de internato, externato ou orfanato.

A Igreja Católica se tornou bastante atuante no campo educacional e seus colégios refletiam a diferenciação de gênero. Segundo Vechia (2005), aos homens era destinado o Ensino Secundário, com um currículo baseado na ciência moderna, enquanto às mulheres era dirigida uma educação para o refinamento cultural, com um programa básico.

Com o Estado Novo, a Igreja Católica conseguiu redobrar sua atuação em relação à educação, favorecida pela sua colaboração com o Governo. Embora sofresse com a disputa de outros grupos, a Igreja conseguiu que membros do catolicismo militante fossem nomeados como agentes públicos influenciadores da política pública, conseguindo com isso a implementação de suas bandeiras, como o Ensino Religioso e a subvenção à sua rede escolar (SCHWARTZMAN, 1986, p. 123).

Claro que havia outros projetos educacionais concorrentes com o do grupo católico. Grupos feministas já faziam reivindicações pela capacitação profissional das mulheres e por igualdade de direitos entre os gêneros desde $o$ início do século XIX (MANOEL, 1996; BUFFA, 2011). Na década de 30 do século $X X$, os escolanovistas entraram em choque com a Igreja Católica ao defenderem a coeducação dos sexos. Não era bem vista pelo grupo católico a inclusão de meninos e meninas na mesma sala de aula (VILHENA, 1992). Neste aspecto, a Igreja Católica marcou algumas vitórias, pois o Estado compartilhava do ideal de que a atuação feminina estava circunscrita ao lar e à religião, sem direito a uma educação e profissionalização igualitária à dos homens.

Uma dessas vitórias fora indicada por Rodrigues e Marques (2007) ao apontarem que, em 1937, introduziu-se um segmento de ensino "dito 'doméstico"' para meninas com idade entre 12 e 18 anos. Esse segmento tinha equivalência "a um ensino médio feminino - que atendia tanto as mulheres de origem humilde, como as mulheres de origem social mais elevada, que pretendiam manter-se como donas de casa."(RODRIGUES; MARQUES, 2007, p.4). 
As escola mistas que passaram a existir traziam a marca da diferenciação de gênero. Os currículos dessas escolas variavam conforme o sexo do público atendido, destinando-se especialmente o ensino de prendas domésticas "ao público discente feminino, na qual se ensinava o trabalho com agulhas, bordados, enfeites, crochê etc." (BENCOSTTA, 2011, p. 74). Também as aulas de Educação Física aconteciam em horários separados para as meninas, demarcando a percepção dos espaços sociais a serem ocupados por homens e mulheres, assim como de seus respectivos papéis na sociedade, fomentando uma cultura escolar correspondente às representações hegemônicas sobre a mulher.

Conforme ainda Bencostta (2011), a única profissão bem vista para a mulher era a docência. No entanto, as diferenciações chegavam ao local de trabalho, verificando-se que em geral as mulheres atuavam no Ensino Primário e os homens no Ensino Secundário, o que implicava, para eles, em melhores salários e possibilidade de assumir cargo de direção escolar.

Até a década de 1960, as representações sobre o papel feminino pouco se modificaram. Como argumentou Del Priore (2013), continuava-se educando as mulheres para formar uma família de respeito na sociedade. Apenas em meados da década citada as coisas começaram a mudar, paulatinamente, com a presença de mulheres no mercado de trabalho, embora com o consentimento do marido, quando casadas. Porém, isso não se deu sem enfrentar a forte resistência à liberalização feminina, aos métodos contraceptivos, ao aborto, ao movimento feminista.

\section{EdUCAÇÃO FEMININA NO AMAPÁ: AS ESCOLAS PARA AS MULHERES}

No Amapá, transformado em Território Federal em 1943, as preocupações relativas à educação feminina estavam em destaque. $O$ novo governo engajava-se não apenas em promover o desenvolvimento econômico da região, mas também o desenvolvimento social. Elegeu-se fomentar uma educação para as mulheres baseada nos valores cristãos e no cultivo de qualidades ligadas ao que seria uma boa esposa e uma boa mãe.

Havia duas instituições públicas consideradas lugares de excelência para tal formação: a Escola Normal de Macapá e a Escola Doméstica de Macapá. Em relação à Escola Normal, sua origem embrionária se deu em 1949, quando fora criado pelo Governo do Território Federal do Amapá (GTFA) o Curso Normal Regional, com o objetivo de suprir a carência de profissionais do magistério no interior do Território, alcançando o estatuto de escola em 1954. Sendo a maioria dos estudantes do sexo feminino, havia uma vigilância constante sobre seu comportamento moral (LOBATO, 2009). 
A Escola Doméstica de Macapá foi criada em 1951 e era dirigida pela ordem católica feminina das Irmãs de Caridade das Santas Capitanio e Gerosa, que chegaram na região um ano antes. Um caráter especial reveste essa escola, o de que mesmo pública, era gerida tanto na parte administrativa quanto na pedagógica pela Congregação feminina, estabelecida no Amapá a convite do administrador apostólico da Prelazia de Macapá (COLOMBO, 2008; LOBATO, 2009; NEGRI, [19--], ROMELLI, 2011). No entanto, Oliveira (2016) destacou que tal vinda já havia há muito sendo desejada em entendimentos antecedentes entre a Igreja Católica e o GTFA, demostrando a interpenetração entre o público e o confessional no projeto afim de desenvolvimento social amapaense. A Escola Doméstica de Macapá funcionou com o regime de internato até 1964, quando foi transformada em Ginásio Feminino de Macapá (GFM). Embora voltada ainda para o público feminino, passou a atender somente como externato. Em fins de 1978, ganhou a nomenclatura de Escola Estadual Irmã Santina Rioli (EEISR), em homenagem a uma das Irmãs de Caridade pioneira no Amapá, e está em pleno funcionamento até os dias atuais, atendendo alunos de ambos os sexos do Ensino Básico.

A Escola Doméstica ministrou um tipo de educação que conciliava o ensino formal, o ensino profissionalizante e o ensino confessional. Investigouse junto às entrevistadas de que forma essa educação recebida gerou ressonâncias nas suas vidas, influindo nas suas escolhas e opções, de modo a perceber se o habitus foi incorporado através da cultura escolar conformada naquela instituição escolar em suas marcas e trajetórias de vida.

Dessa maneira, uma das ressonâncias identificadas foi a influência da cultura escolar sobre o papel social que as egressas assumiram ao sair da escola, conforme Antonia (apud OLIVEIRA, 2016, p. 176): "na minha formação como mãe, como esposa, na minha vida religiosa, contribuiu muito. Principalmente na vida religiosa eu aprendi muita coisa lá e até hoje eu não me esqueço de tudo o que eu aprendi sobre religião. Eu me dedico mesmo muito à religião."

As egressas saíam da escola com a convicção de que estavam preparadas para a vida e seu futuro, como explicitou Joana d'Arc: "preparar para vida, para o futuro porque nós, como mulheres, devíamos ser domésticas mesmo, né? Aprender a fazer uma alimentação, aprender a costurar. Preparar para ser dona de casa!" (apud OLIVEIRA, 2016, p. 176).

A Escola Doméstica trouxe para Benedita diversos tipos de aprendizagem, tanto no trato com as pessoas, quanto na conscientização de seus deveres como dona de casa, que conciliava com a profissão de professora: "Foi lá que eu aprendi a ter uma educação, saber tratar e respeitar 
as pessoas, [...]. Onde eu aprendi a ser mulher, gostar de trabalhar, não ter medo de trabalho, gostar de limpar"(BENEDITA apud OLIVEIRA, 2016, p. 176).

O costume de gostar de trabalhar e de limpar era absorvido também pela cultura escolar da Escola Doméstica. Como apontaram as entrevistadas anteriormente, elas faziam o serviço de limpeza da escola em escala de 15 dias, começando as atividades desde o amanhecer, conciliadas com os momentos de estudo e os cultos religiosos. Para Nadir, todas as regras e normas dentro da escola foram importantes porque complementavam a aprendizagem materna: "eu já era colocada dentro do esquema por causa da minha mãe de criação. E aquilo foi melhor porque dominou mais. Me incentivou! Valeu! Pena que eu não tenha conseguido terminar, mas Deus sabe o porquê" (apud OLIVEIRA, 2016, p. 176).

Esse aspecto ficou bem marcado em Semina, que incorporou especialmente o tempo curto para tomar banho por conta do castigo que levou nesse sentindo: "Mas olha, serviu! Serviu! Até hoje eu não demoro no banho e todo mundo em casa sabe que eu não demoro. Quando alguém demora muito eu digo para pessoa: eu dou para você o castigo que eu levei." Essa marca poderia ter gerado em Semina algum tipo de trauma ou aversão à Escola Doméstica, mas para ela a aprendizagem teve aspectos positivos:

pela lição de vida que tive aqui, pelo coleguismo, pela orientação para vida, assim. Tanto é que eu fiz questão de terminar aqui minha carreira, [referindo-se a estar trabalhando justamente na atual E. E. Irmã Santina Rioli]. E eu estou aqui desde 1992, há 23 anos (apud OLIVEIRA, 2016, p. 177).

Semina é professora e desempenha suas funções no local que um dia foi a Escola Doméstica, com atividades na coordenação escolar. O seu vínculo com a escola foi tão forte que ela preferiu, ao contrário de todas as outras alunas, trabalhar no mesmo lugar em que passou parte da sua juventude. No entanto, ela foi a única dentre as entrevistadas que evidenciou ter levado um choque de realidade após ter-se formado, deixando a emoção aflorar ao revelar que: "teve coisas que aconteceram na minha vida que quando eu me lembro que as feiras me diziam que era isso, isso e isso! Teve um dia que eu estava tão revoltada que eu queria achar aquelas freiras na minha frente que eu ia dizer para elas..." Nem todas as orientações que as Irmãs de Caridade davam às alunas podiam corresponder aos desafios que teriam a enfrentar fora da escola, podendo-se correlacionar com as transformações da sociedade e as novas exigências ao papel feminino, com o transcorrer do tempo, ou com questões de ordem pessoal. 
As entrevistadas, na medida do possível, procuraram constituir famílias sadias e cristãs, conforme o padrão moral da época e apreendido na escola. Apenas uma delas revelou não ter dado sorte na primeira vez que se casou, mas não por culpa dela. Também sempre estavam às voltas com questões da fé, sendo isso até hoje um componente importante no sentido que deram às suas vidas. Benedita tentou seguir a vida religiosa e Maria de Lourdes passou anos indecisa se deveria ou não se tornar freira. Por sua vez, Maria Raimunda correlacionou da seguinte forma a influência que o ensino confessional teve sobre ela:

Olha, foi uma benção de Deus! Porque eu creio, como te disse, nós estávamos num pedacinho de Céu! Nós tínhamos aulas de Religião, também. Naquele tempo tínhamos que fazer até prova. Prova de Religião, sim, senhora! Que também reprovava, naquele tempo. $\mathrm{E}$ foi assim porque nós tínhamos missa todos os dias. [...] Então nós tínhamos aquela comunhão com Deus: aprendemos a amar a Deus sobre todas as coisas. Foram esses ensinamentos que as irmãs nos passaram. E se hoje o meu encontro com Deus está da forma que está foi por causa disso. Hoje eu sou ministra da Eucaristia na minha Igreja, aqui na Santa Inês (apud OLIVEIRA, 2016, p. 177).

Maria Raimunda possui um altar na sua residência contendo imagens de diversas santas, especialmente da Virgem Maria. Com muito orgulho, explicou como adquiriu cada uma em suas viagens e sobre as novenas que acontecem em sua casa. Uma imagem em especial chamou a atenção, conforme a Foto 1, na qual se identifica ao centro a imagem de Nossa Senhora Maria Menina, a padroeira da Irmãs de Caridade do Instituto de Caridade das Santas Capitanio e Gerosa, o que fez associar a devoção à continuação de uma prática religiosa da Escola Doméstica, onde todos os anos havia a festa da padroeira na escola, conforme os Relatórios de atividades da Escola Doméstica. 
Foto 1 - Altar na casa de Maria Raimunda Ramos, com destaque à imagem de N. S. Menina.

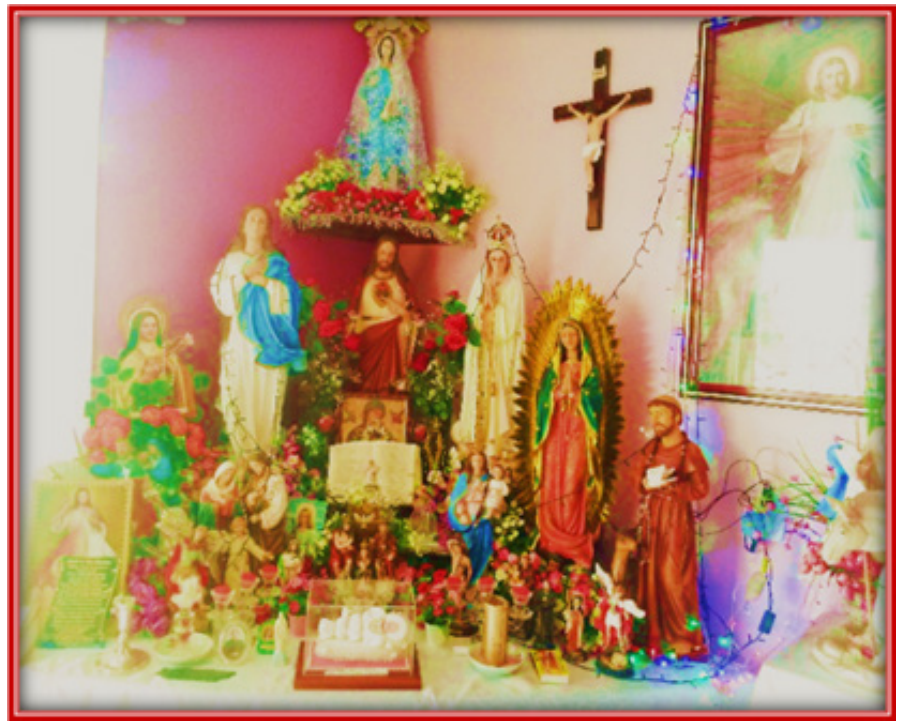

Fonte: acervo pessoal da autora, com a devida autorização da entrevistada (2015).

A prática religiosa de rezar o terço ficou como uma marca para Maria Yolanda, que até hoje cumpre o ato todos os dias às madrugadas:"O costume veio de lá. A gente rezava o terço. Rezava o rosário, né? Só não me lembro muito bem os horários. Parece que era de manhã, antes da missa, e seis horas da tarde. Foi muito bom! Bom, bom mesmo" (AMAPÁ/EDM, 1951-1964).

Para Antonia a aprendizagem na Escola Doméstica associava a preparação para o casamento à formação religiosa. Esta é uma marca que Ihe dá bastante orgulho ao comentar que: "até hoje, eu estou com 73 anos, mas ainda não expulsei minha religião. Deus o livre! A semana que eu não vou a todas minhas novenas, minha missa dia de domingo parece que não é legal. Minha formação religiosa foi muito boa" (apud OLIVEIRA, 2016, p. 178).

Em relação à profissionalização feminina, que era um dos objetivos da Escola Doméstica, as entrevistadas apontaram três opções tomadas em suas vidas, mas sem que uma excluísse a outra necessariamente: uma foi a escolha pela vida profissional como artesãs de artes domésticas, outra foi a dedicação a seus dons artísticos e ao lar, e a terceira via foi procurar continuar seus estudos para a docência. Sobre a primeira opção, observe-se o depoimento de Joana d'Arc: 
Era esse o futuro: aprender e também no futuro ter uma vida profissional, para aprender a fazer e vender para ganhar um tostão para o sustento. Foi o que aconteceu comigo. Quando eu casei, eu fiz muita coisa de crochê. Até hoje ainda faço. Não me esqueci! Eu fiz muita meinha para criança, sapatinhos, agasalhos... logo quando eu casei. Porque eu não tinha renda! (apud OLIVEIRA, 2016, p. 178).

Após seu casamento, Joana d'Arc viu que as habilidades adquiridas na Escola Doméstica e, depois, no Ginásio Feminino serviam muito bem para complementar a renda familiar, uma vez que ela não trabalhava fora, dedicando-se a ser dona de casa. Somente depois de algum tempo ela procurou dar continuidade aos seus estudos e seguir a carreira de professora. Mas até hoje ela procura ainda, na medida do possível, trabalhar nas encomendas de crochê, conforme se vê na Foto 2, atividade de que mais gostava na sua época de estudante.

Foto 2 - Toalha de mão bordada e ornamentada com crochê, por Joana d'Arc.

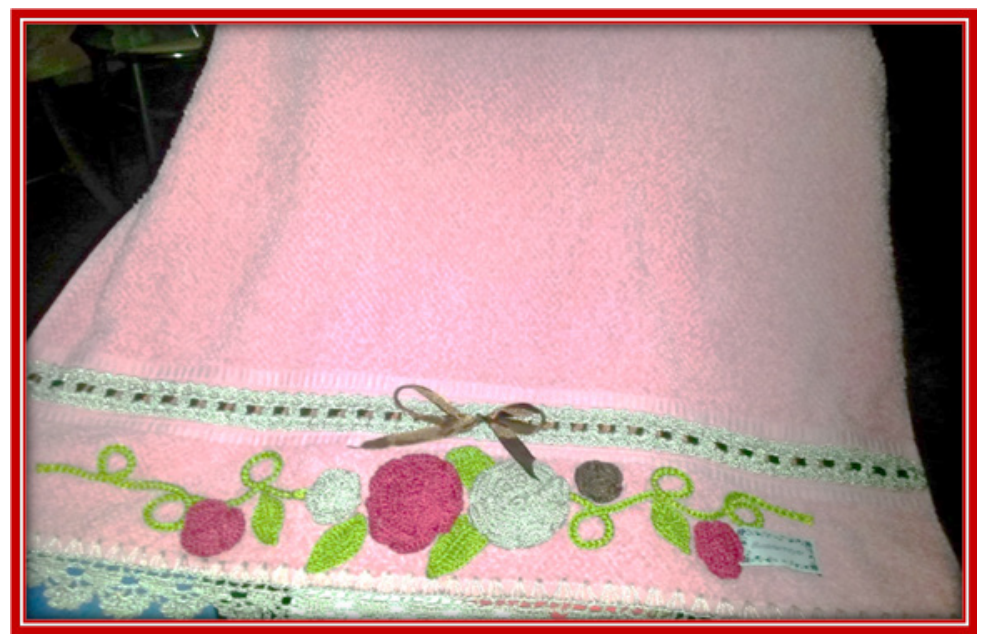

Fonte: acervo pessoal da autora, com a devida autorização da entrevistada (2015).

Maria Yolanda também disse que se dedicou durante muito tempo às encomendas de prendas domésticas, especialmente usando o ponto cruz, aplicação e o crochê:

Ponto de cruz a irmã batalhou, mas eu aprendi. Aplicar, eu gostava muito de fazer trabalho aplicado. Demais mesmo! Eu fazia, eu vendia, sabe, lençóis de cama! Eu fazia aqueles lençóis enormes, tudo bordado, cortinas de berço, 
enxoval para bebê, eu fazia tudinho. Não tinha nesse tempo para vender aqui, né? E eu fazia de cambraiazinha, pregava renda, tudo na mão, fechava tudinho fazendo ponto atrás. [...] Eu aprendi a bordar lá. Depois de casada, eu fazia camisinha para recém-nascido, mana, eu ganhava meu dinheiro. Fazia enxoval tudo à mão! Fazia ponto Paris, ponto não sei o quê, aqueles bordados riachuelo, né? Agora não, que eu não enxergo direito. Eu quero fazer, mas não posso mais! Ganhei muito dinheiro, mana! (apud OLIVEIRA, 2016, p. 179),

As entrevistadas revelaram até hoje gostar de fazer as atividades de artes domésticas que aprenderam na escola e também de estar trabalhando ativamente na limpeza e cuidados com o lar, mas devido aos problemas de saúde e de visão advindos com o avanço da idade, elas são tolhidas de continuar, o que as deixa um pouco frustradas.

Esse é o caso também de Hercília, que preferiu fazer trabalhos de prendas para o usufruto seu e de sua família, tentando passar o conhecimento aprendido para a sua filha: "não fiz trabalho para vender. Só para mim! Eu aprendi o crochê, depois um pouquinho. Tudo que ela [refere-se à sua filha] sabe, eu que ensinei para ela: o ponto cruz, o ponto sombra, o ponto cheio, entendeu. Tudo! [...]"(apud OLIVEIRA, 2016, p. 179).

Igual foi a situação de Maria Raimunda, que optou por não aceitar encomenda de trabalhos, usando as habilidades adquiridas em proveito próprio, até o presente momento: "eu gosto sempre de fazer minha roupa mesmo porque não gosto das roupas que estão no comércio [...]. Até as meninas [suas filhas] brigam comigo: olha mamãe, a sua vista já não dá. Realmente, eu fico com a vista muito cansada!".

O terceiro leque de opção seguido foi o da docência. Verifica-se que 6 dentre as 10 egressas tornaram-se professoras em algum período de suas vidas. Mas somente três entrevistadas, Joana d'Arc, Antonia e Semina, apontaram a necessidade de continuar os estudos e fazer o curso de férias do Curso Normal Regional, que habilitava regentes do Ensino Primário a lecionarem no interior do Território Federal do Amapá.

Joana d'Arc passou algum tempo se dedicando à família e trabalhando em encomendas de prendas doméstica antes de seguir os estudos no magistério. Antonia considera que a sua formação na Escola Doméstica serviu para o casamento, mas não para conseguir um emprego, coisa que só buscou depois de alguns anos:

Eu me formei no pedagógico em 1975. Eu saí da Escola Doméstica em 1960. Já trabalhava e era casada quando comecei estudar o pedagógico. $E$ aí estava todo mundo apelando para fazer o pedagógico porque o nosso curso ficou sem, assim, uma validade de emprego. Não teve para nada que 
a gente levou até pro curriculum. Não constava! Eles não aceitavam" (apud OLIVEIRA, 2016, p. 180).

Semina também apontou que muitas ex-alunas procuraram depois seguir o caminho do magistério. Neste caso, a formação na Escola Doméstica serviu bastante, pois: "tempos depois, tinha Educação para o lar e a gente era aproveitada como professora desta matéria, que saiu do currículo, pela outra nova Lei foi extinta" (apud OLIVEIRA, 2016, p. 180).

Analisar-se-á agora a autobiografia de Zeneide (SOUZA, 2013), procurando as principais marcas que a Escola Doméstica deixou em sua vida. Destaca-se primeiramente que Zeneide é atualmente médica aposentada, mas que, em sua trajetória, seguiu logo no início a mesma opção de Semina, participando dos cursos de férias e conseguindo emprego como professora regente do Ensino Primário no interior do Território do Amapá.

Zeneide (SOUZA, 2013), conforme relata em sua obra, foi uma aluna indisciplinada e questionadora das regras e normas da escola, por muitas vezes quebrando a ordem e sendo castigada por isso. É a única dentre as ex-alunas aqui mencionadas que revelou ter sofrido castigos físicos, que a deixavam mais revoltada. Também deixa transparecer que todo aquele sistema a oprimia, sentindo-se como um pássaro em uma gaiola, sendo libertada no dia da sua formatura. O trauma teria sido tão grande que ela passou anos sem passar sequer na frente da Escola Doméstica.

Diante desse quadro, verifica-se que por mais que resistisse à cultura escolar, acabou adquirindo habitus e, por incrível que pareça, reproduzindo-o em sua prática docente quando, em sua primeira turma, admitiu adotar "os mesmos métodos da Escola Doméstica, com sucesso" (SOUZA, 2013, p. 90). Infelizmente, ela não esclareceu na sua autobiografia que métodos foram estes. $O$ sucesso a que ela se referiu foi a aprovação de todos os seus alunos nos exames finais.

A aprendizagem na Escola Doméstica também foi-lhe útil para progredir na carreira do Magistério. Aproveitou-se da oportunidade de prestar um processo seletivo para estudar Cursos de Artes Industriais fora do Amapá. Nesta seleção, conseguiu aplicar suas habilidades em pintura e artes manuais, que adquiriu na escola, e obter aprovação para uma das vagas requeridas.

Algumas marcas negativas foram atribuídas por Zeneide aos castigos que recebera na Escola. Uma delas foi a sensibilidade no couro cabeludo em virtude dos puxões de cabelo que levava das Irmãs por se despir e gargalhar, afrontando as normas de pudor segundo as quais não se podia mostrar nudez, coisa que ela diz não haver sentido, por ter corpo de criança, à época. Outra consequência de um castigo - encontrar sua mãe hospitalizada, sem aviso 
prévio por parte das Irmãs, no dia em que fez 15 anos de idade - foi aventada por Zeneide como a influência na escolha da sua especialização médica em cirurgia plástica e na mania de dar presentes de aniversário, já que ficou com trauma do seu 'presente' de 15 anos.

Mas nem tudo parece ter deixado marcas tão negativas. Na festa de comemoração do cinquentenário da escola, a qual Zeneide ajudou a organizar, estavam presentes duas Irmãs que lecionaram na Escola Doméstica. A autora pediu perdão ao microfone por suas estripulias e confessou suas estratégias para tirar boas notas e continuar na escola. Foi um momento de confraternização entre ela e as referidas freiras.

\section{ConsiderAÇÕES FINAIS}

A investigação sobre a assimilação de habitus que foi engendrado pela cultura escolar da Escola Doméstica de Macapá buscou averiguar de que maneira, na trajetória de vida das egressas, as opções e as escolhas que fizeram em suas vidas estiveram ligadas ao seu sistema de percepção incorporado, seguindo a linha teórica proposta por Pierre Bourdieu.

Dessa forma, encontraram-se marcas e reminiscências nos relatos das alunas, algumas atribuindo uma carga positiva e outras nem tanto às suas experiências escolares. Ficou nítido que a Escola Doméstica conseguiu influenciar no papel social que suas ex-alunas assumiram como mães, esposas e donas de casa. As normas e regras da escola, que constituíram parte da sua cultura escolar, moldaram os gostos e costumes das ex-alunas, sendo que a formação religiosa deixou-lhes um forte traço de fé e espiritualidade.

Observou-se que algumas egressas criaram certas expectativas para o futuro, que no viver da realidade acabaram tornando-se desilusões. A sociedade brasileira passou por momentos de intensas transformações e questionamentos sobre a ideia do que era ser mulher e qual o papel que deveria desempenhar no transcorrer da década de 1960. Também os castigos físicos deixaram traumas de infância de difícil superação.

Outro traço a ser registrado é o da profissionalização feminina. Três leques de atuação foram identificados: o de artesãs de artes domésticas, emprego de habilidades artísticas em prol de sua família, e a possibilidade de continuar os estudos na área de docência. Muito embora essas trajetórias pudessem implicar em trabalho para ou fora do lar, a intencionalidade do GTFA era de que as mulheres constituíssem renda complementar à do marido, esse sim o chefe e provedor da família. A docência para as mulheres, conforme as representações da época, era uma profissão eminentemente feminina que não comprometia seu papel dentro do lar. 
A Escola Doméstica de Macapá conseguiu gerar a incorporação de habitus no seu período de vigência e permitiu a sua reprodução, contribuindo desse modo para a realização dos desígnios do projeto governamental de conjugação do desenvolvimento socioeconômico e cultural do Território Federal do Amapá. Desenvolvimento esse que considerava a mulher a base de formação de uma nova sociedade, trabalhadora e disciplinada, numa divisão sexual do trabalho que encarregava a população feminina dos trabalhos domésticos e de mãe e esposa.

Artigo recebido em: 25/08/2017

Aprovado para publicação em: 23/03/2018

FEMALE EDUCATION ON THE FRONTIER OF THE AMAZON: SCHOOLS FOR WOMEN IN THE FEDERAL TERRITORY OF AMAPÁ (1949-1964)

ABSTRACT: This paper contextualizes the debate on female education in Brazil and Amapá, combining bibliographical and empirical research, using oral history methodology, to the analysis of the semi-structured interviews, given by 9 former students of the Macapá Domestic School, and the report of one former student, which is condensed in an autobiography. It presents one of the results of the master's dissertation Public/ confessional, school culture and habitus formation: the Domestic School of Macapá/AP (1951-1964), dealing with the incorporation of habitus through the school culture of that school. The theoretical underpinning takes on the concept of habitus, by Pierre Bourdieu, and of school culture, by Dominique Julia.

KeYwords: School culture. Female education. Habitus. Catholic Church. State.

EDUCACIÓN FEMENINA SOBRE LA FRONTERA DE LA AMAZONIA: ESCUELAS PARA MUJERES EN EL TERRITORIO FEDERAL DE AMAPÁ (1949-1964)

RESUMEN: Este trabajo contextualiza el debate sobre la educación femenina en Brasil y en Amapá, conjugando la investigación bibliográfica y la empírica, utilizando la metodología de la Historia Oral en el análisis de las entrevistas semiestructuradas, concedidas por nueve ex-alumnas de la Escuela Doméstica de Macapá, además de los relatos de la $10^{\text {a }}$ egresada, condensados en una autobiografía. Presenta uno de los resultados de la tesis de maestría "público/confesional, cultura escolar y formación de habitus: la Escuela Doméstica de Macapá/AP (1951-1964)", disertando sobre la incorporación de habitus a través de la cultura escolar de la escuela citada.. La base 
teórica se refiere al concepto de habitus, de Pierre Bourdieu, y de cultura escolar, de Dominique Julia.

Palabras Clave: Estado. Iglesia Católica. Educación Femenina Cultura escolar. Habitus.

\section{REFERÊNCIAS}

AZZI, R. A lgreja Católica na formação da sociedade brasileira. Aparecida: Santuário, 2008.

BENCOSTTA, M. L. A. Grupos escolares no Brasil: um novo modelo de escola primária. In:STEPHANOU, M.; BASTOS, M. H. C. (Org.). Histórias e memórias da educação no Brasil (século XX). 4. ed. Petrópolis: Vozes, 2011. (3 v.).

BOURDIEU, Pierre. Razões práticas: sobre a teoria da ação. Tradução: Mariza Côrrea. 11. ed. Campinas: Papirus, 2011.

BUFFA, E. O público e o privado na educação brasileira do século XX. In: STEPHANOU, M.; BASTOS, M. H. C. (Org.). Histórias e memórias da educação no Brasil (século XX). 4. ed. Petrópolis: Vozes, 2011. 3 v.

COLOMBO, M. Aristides Pirovano: o bispo de dois mundos. Tradução: José Afonso Beraldin. Porto Alegre: Centro de Espiritualidade e Cultura Calabriana, 2008.

CUNHA, W. D. dos S.; SILVA, R. J. V. A educação feminina do século XIX: entre a Escola e a literatura. Gênero online, Niterói, v. 11, n. 1, p. 97-106, jul./dez. 2010. Disponível em: <http://www.revistagenero.uff.br/index.php/revistagenero/article/view/62>. Acesso em: 2 abr. 2015.

DEL PRIORE, M. Conversas e histórias de mulher. São Paulo: Planeta, 2013.

JULIA, D. A cultura escolar como objeto histórico. Tradução: Gizele de Souza. Revista Brasileira de História da Educação online, Maringá, n. 1, p. 9-43, jan./jun. 2001. Disponível em: <http://www.scielo.br/pdf/ep/v30n1/a08v30n1.pdf>. Acesso em: 10 maio 2015.

LOBATO, S. Educação na fronteira da modernização: a política educacional no Amapá. Belém: Paka-Tatu, 2009.

MANOEL, I. A. Igreja e educação feminina (1859-1919): uma face do conservadorismo. São Paulo: UNESP, 1996.

NEGRI, T. Dom Aristides: uma aventura humana e missionária. São Paulo: Mundo e Visão, [19--].

OLIVEIRA, T. P. O. Público/confessional, cultura escolar e formação de habitus: a Escola Doméstica de Macapá/AP (1951-1964). 2016. 205 f. Dissertação (Mestrado em Desenvolvimento Regional) - Programa de Mestrado em Desenvolvimento Regional da Universidade Federal do Amapá, 2016. 
RODRIGUES, J. M.; MARQUES, E. C. de R. O civilizar da mulher na história da educação. In: CONGRESSO DE LETRAS, 4., 2007, Caratinga. Anais eletrônicos... Caratinga: UNEC, 2007.7 p. Disponível em: <http://bibliotecadigital.unec.edu.br/ojs/index.php/unec03/ article/viewFile/310/386>. Acesso em: 28 nov. 2015.

ROMELLI, G. 50 Anos educando para a vida: uma proposta diferente [1961-2011]. Macapá: [s.n.], 2011.

SCHWARTZMAN, S. A política da Igreja e a educação: o sentido de um pacto. Religião e Sociedade, Rio de Janeiro, v. 13, n. 1, mar. 1986. Disponível em: <https://ia600806. us.archive.org/24/items/APoliticaDalgrejaEAEducacaoOSentidoDeUmPacto1986_85 9/1986alceu.pdf>. Acesso: 14 jul. 2015.

SOUZA, Z. A. de. Desafios de uma cirurgiã plástica na Amazônia. Fortaleza: Premius, 2013. $239 \mathrm{p}$.

STAMATTO, M. I. S. Um olhar na História: a mulher na Escola (1549-1910). In: CONGRESSO BRASILEIRO DE HISTÓRIA DA EDUCAÇÃO: história e memória da educação brasileira, 2., 2002, Natal. Anais eletrônicos... Natal: UFRN, 2002. Disponível em: <www. sbhe.org.br/novo/congressos/cbhe2/pdfs/Tema5/0539.pdf>. Acesso em: 4 set. 2015.

VECHIA, A. O ensino secundário no século XIX: instruindo as elites. In: STEPHANOU, M.; BASTOS, M. H. C. (Org.). Histórias e memórias da educação no Brasil (século XIX). Petrópolis: Vozes, 2005, p. 78-90. (2 v.).

VILHENA, C. P. de S. A família na Doutrina Social da Igreja e na política social do Estado Novo. Psicologia-USP, São Paulo, v. 1/2, n. 3, p. 45-57, 1992. Disponível em: <http:// pepsic.bvsalud.org/scielo.php?pid=S1678-51771992000100005\&script=sci_arttext $>$. Acesso em: 30 jan. 2015.

Tatiana Pantoja Oliveira: Mestre em Desenvolvimento Regional pela Universidade Federal do Amapá (PPGMDR/UNIFAP). Especialista em História Social e Cultural da Amazônia e possui graduação em História. É professora de História da rede pública de ensino do Governo do Estado do Amapá.

E-mail: tatiapantoja@smail.com

Norma-Iracema de Barros Ferreira: Professora da UNIFAP na Graduação e na Pós-Graduação latu e stricto senso. Doutora em Educação Escolar/UNESP. Mestre em Psicologia da Educação/FGV-RJ. Graduada em Psicologia e em História/UFPA.

E-mail: normairacemaunifap@smail.com 
